THE EFFECT OF IMAGE ENHANCEMENTS AND DUAL OBSERVERS ON PROXIMAL CARIES DETECTION

\title{
Benjamin Gray
}

\begin{abstract}
A thesis submitted to the faculty at the University of North Carolina at Chapel Hill in partial fulfillment of the requirements for the degree of Master of Science in Oral and Maxillofacial Radiology in the School of Dentistry.
\end{abstract}

\section{Chapel Hill}

2016

Approved by:

Donald Tyndall

André Mol

Andrea Zandoná 
(C) 2016

Benjamin Gray

ALL RIGHTS RESERVED 


\begin{abstract}
Benjamin Gray: The effect of image enhancements and dual observers on proximal caries detection (Under the direction of Donald Tyndall)
\end{abstract}

New technologies, including image enhancements, have been developed in order to increase diagnostic accuracy for caries detection. Very little data exists as to whether or not these enhancements actually improve accuracy. Low technology solutions to improving early caries diagnosis, such as using dual observers, have not been tested. Our aims were to determine if certain image enhancements and dual observers had an effect on three diagnostic tasks. Seven observers viewed unenhanced and enhanced images taken on PSP and Schick 33 sensors and were asked to determine whether proximal caries lesions, dentin extension, and cavitation were present. Pairs of observers also evaluated the unenhanced PSP images and recorded their confidence. Micro-CT was used as the gold standard. For caries lesion detection, PSP outperformed Schick 33 sensors. Observers (single and dual), filters, and receptors had no effect on the other diagnostic tasks. Observers were more reliable in detecting dentin extension with Schick sensors. 


\section{ACKNOWLEDGEMENTS}

Special thanks are due to The Dental Foundation of North Carolina for their generous award which enabled us to use the Small Animal Imaging Core facility at the UNC Biomedical Imaging Research Center for acquiring the micro-CT images. We would also like to thank Dr. Laurence Gaalaas for helping acquire the images and Dr. Ceib Phillips for help with developing the statistical plan. 


\section{TABLE OF CONTENTS}

LIST OF TABLES




\section{LIST OF TABLES}

Table 1 - Proximal surface ground truth status by micro-CT ..................................................... 18

Table 2 - Presence of dental caries lesion $A_{z}$ values ............................................................ 19

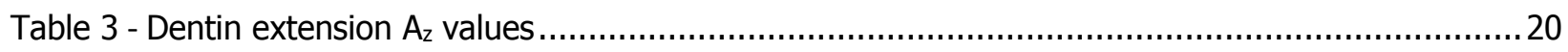

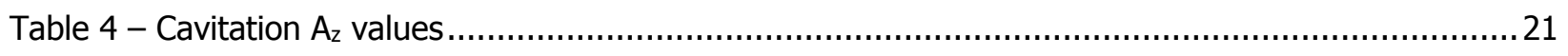

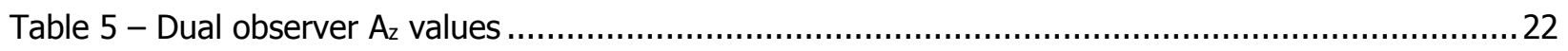

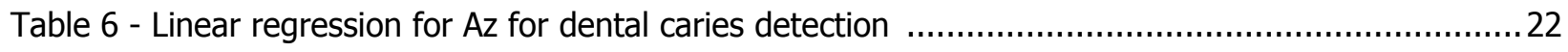

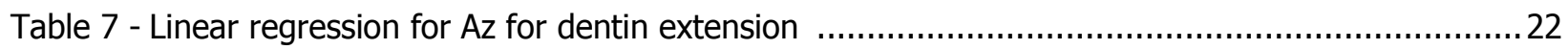

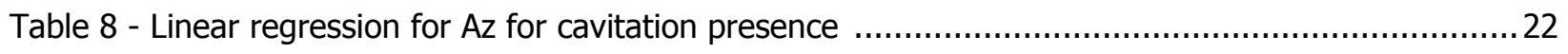

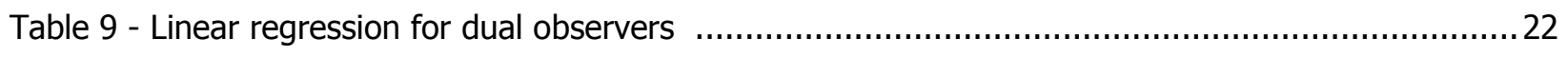

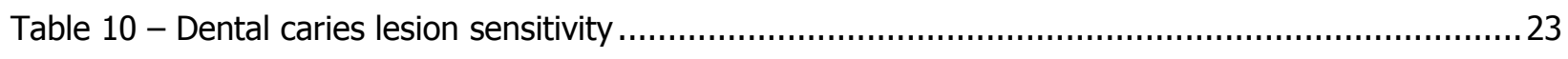

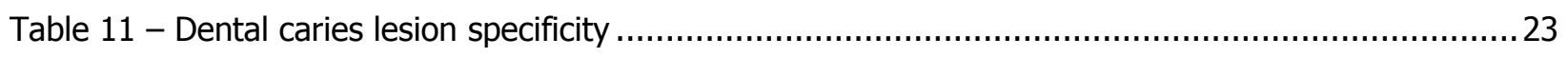

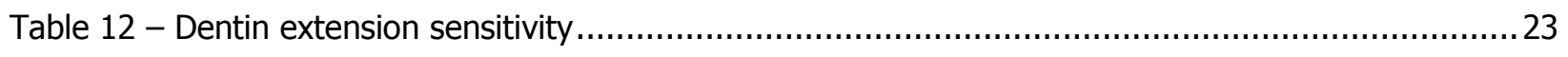

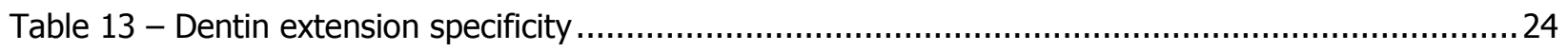

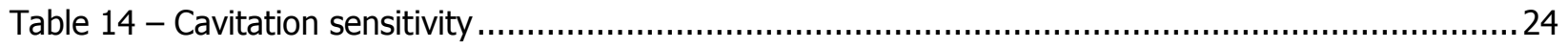

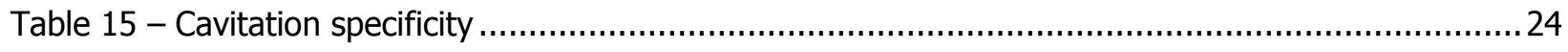

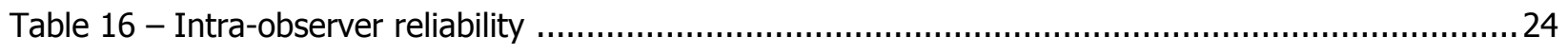

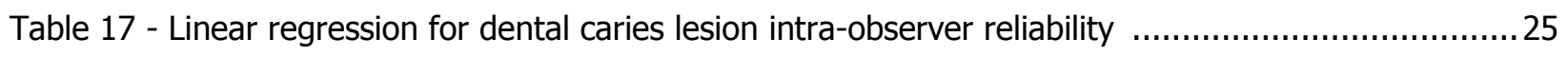

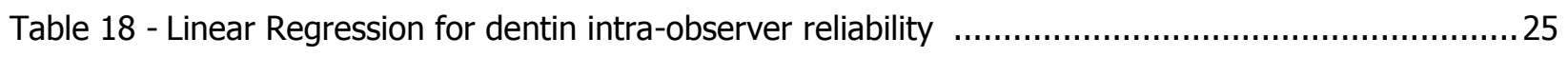

Table 19 - Linear Regression for dentin Intra-observer reliability .................................................25

Table 20 - Linear regression for dental caries lesion specificity .................................................25 


\section{LIST OF FIGURES}

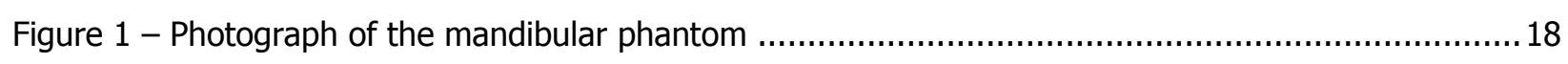

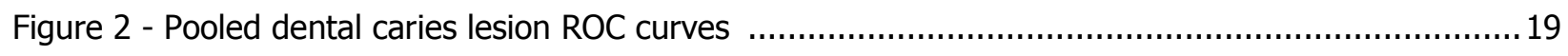

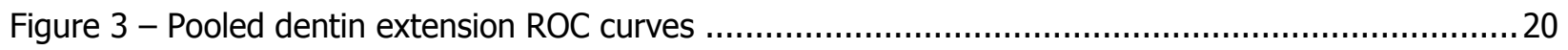

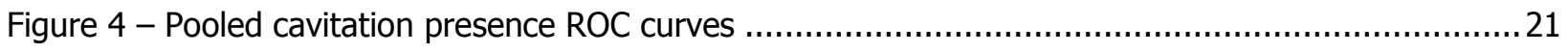




\section{LIST OF ABBREVIATIONS}

$\begin{array}{ll}\text { ANOVA } & \text { analysis of variance } \\ \text { Az } & \text { area under the ROC curve } \\ \text { CBCT } & \text { Benjamin Gray (primary investigator) } \\ \text { DT } & \text { cone beam computed tomography } \\ \text { HD } & \text { thesis mentor (Donald Tyndall) } \\ \text { IRB } & \text { institutional review board } \\ \text { HSV } & \text { micro-Sieverts } \\ \text { micro-CT } & \text { micro-computed tomography or microtomography } \\ \text { PI } & \text { primary investigator (Benjamin Gray) } \\ \text { PSP } & \text { photostimulable phosphor (bitewings) } \\ \text { ROC } & \text { receiver operating characteristic (curve) } \\ \text { Schick33 } & \text { Schick 33 direct digital bitewings } \\ \text { UNC } & \text { University of North Carolina at Chapel Hill }\end{array}$




\section{REVIEW OF THE LITERATURE}

Dental caries is one of the most common diseases affecting man. It is a progressive and cumulative condition which when left untreated, destroys the hard tissues of the mouth and leads to increased patient morbidity and cost of treatment. ${ }^{1,2}$ A disproportionate amount of the caries burden in the US rests with those who do not have the necessary resources to correct dental related conditions. ${ }^{2}$ In 2012 , total national dental expenditures in the US reached $\$ 111$ billion dollars. ${ }^{3}$ Since the loss of tooth structure due to caries often requires invasive, surgical restoration methods which lead to a cascade of treatments for the lifetime of the patient, prevention and early detection of disease which can be treated non-invasively will reduce the overall health care cost for the individual and society as a whole. ${ }^{1} \mathrm{~A}$ paradigm shift has taken place in dentistry where emphasis is now being placed on preventative care rather than aggressive operative techniques to control the caries disease process.

Non-surgical treatment of early carious lesions is less expensive and results in less destruction of oral structures. ${ }^{1,4-6}$ Understanding which lesions will progress rather than arrest or remineralize, is essential to developing the appropriate treatment plan for individual patients. Along with current lesion activity, lesion depth and cavitation status are important factors to consider prior to initiating treatment. - $^{-}$

8 Non-cavitated lesions in the enamel or slightly past the DEJ can successfully be treated by application of fluoride varnish rather than costly, invasive, surgical procedures. ${ }^{9}$ Lesions that progress into the dentin and that show signs of cavitation are much less likely to be arrested or remineralized. ${ }^{7}$

In order to accurately detect the carious process, a highly sensitive and specific diagnostic test is needed. By far the most commonly used and best accepted modality for detection of the proximal carious process is the use of intraoral bitewing radiography evaluated by trained clinicians. ${ }^{10,11}$ In order to maximize patient benefit from a radiological exam in terms of detection of decay caused by oral bacteria, a radiographic detection system should be able to record the entire spectrum of the demineralization 
process. ${ }^{12}$ The detection system should be both sensitive to the subtle contrast changes taking place in the enamel and dentin, and specific for demineralization caused by cariogenic bacteria. ${ }^{12-15}$ Caries detection is a contrast dependent diagnostic task rather than a resolution dependent one and thus bitewing radiography should ensure high intra-tissue contrast in order to answer diagnostic questions such as depth penetration and cavitation status. ${ }^{13,14}$ Previous studies have shown however, that it does not provide an accurate medium for either task. ${ }^{16-19}$

Despite the enormous financial investment into digital sensor technology, no significant increase in caries detection has been seen since early film based systems. ${ }^{10,17,20-26}$ While digital technology allows for enhancement of images, added convenience, and decreased processing time, no significant increase in diagnostic accuracy has been seen. ${ }^{13,14,26}$ Many companies have introduced caries detection task specific image enhancement filters designed to improve detection of early lesions. While some studies have shown promise using these filters, others have shown little to no improvement in early detection. ${ }^{27-}$ 32 Due to the numerous manufacturers of dental, digital imaging software and systems, many of these filters remain untested.

Observer performance in the detection of carious demineralization has remained fairly constant in the past few decades, hovering around $60 \% \cdot{ }^{10,11}$ Heaven looked at the effects that multiple examinations with multiple observers had on sensitivity and specificity. He found that increasing group size resulted in an increase in sensitivity. ${ }^{33}$ To date no studies have been published looking at whether dual observers viewing bitewing radiographs at a single time point results in an increase of diagnostic accuracy. Since the number of dental practices with more than one dentist has increased drastically in the past decade, this low tech detection aid may be an alternative to software enhancements. ${ }^{34}$ 


\section{REFERENCES}

1. Schwendicke F, Meyer-Lueckel H, Stolpe M, Dorfer CE, Paris S. Costs and effectiveness of treatment alternatives for proximal caries lesions. PloS one. 2014;9(1):e86992.

2. Services UDoHaH. Oral Health in America: A Report of the Surgeon General. U.S. Department of Health and Human Services, National Institute of Dental and Craniofacial Research, National Institutes of Health 2000.

3. Wall T, Nasseh K., Vujicic M. U.S. Dental Spending Remains Flat through 2012. Health Policy Resources Center Research Brief. American Dental Association.

4. Diagnosis and management of dental caries throughout life. National Institutes of Health Consensus Development Conference statement, March 26-28, 2001. Journal of dental education. 2001;65(10):1162-1168.

5. Selwitz RH, Ismail Al, Pitts NB. Dental caries. Lancet (London, England). 2007;369(9555):51-59.

6. Baelum V. What is an appropriate caries diagnosis? Acta odontologica Scandinavica. 2010;68(2):65-79.

7. Kidd EA, Fejerskov $\mathrm{O}$. What constitutes dental caries? Histopathology of carious enamel and dentin related to the action of cariogenic biofilms. Journal of dental research. 2004;83 Spec No C:C35-38.

8. Stahl J, Zandona AF. Rationale and protocol for the treatment of non-cavitated smooth surface carious lesions. General dentistry. 2007;55(2):105-111.

9. Lenzi TL, Montagner AF, Soares FZ, de Oliveira Rocha R. Are topical fluorides effective for treating incipient carious lesions?: A systematic review and meta-analysis. Journal of the American Dental Association (1939). 2016;147(2):84-91.e81.

10. Senel B, Kamburoglu K, Ucok O, Yuksel SP, Ozen T, Avsever H. Diagnostic accuracy of different imaging modalities in detection of proximal caries. Dento maxillo facial radiology. 2010;39(8):501-511.

11. Dove SB. Radiographic diagnosis of dental caries. Journal of dental education. 2001;65(10):985990.

12. Zandona AF, Zero DT. Diagnostic tools for early caries detection. Journal of the American Dental Association (1939). 2006;137(12):1675-1684; quiz 1730.

13. Huda W, Rill LN, Benn DK, Pettigrew JC. Comparison of a photostimulable phosphor system with film for dental radiology. Oral surgery, oral medicine, oral pathology, oral radiology, and endodontics. 1997;83(6):725-731.

14. Kashima I. Computed radiography with photostimulable phosphor in oral and maxillofacial radiology. Oral surgery, oral medicine, oral pathology, oral radiology, and endodontics. 1995;80(5):577598. 
15. Webber RL, Benton PA, Cvar JF, Ryge G. Diagnostic significance of intratissue contrast in bitewing radiographs. Oral surgery, oral medicine, and oral pathology. 1969;28(3):352-358.

16. Wenzel A. Radiographic display of carious lesions and cavitation in approximal surfaces: Advantages and drawbacks of conventional and advanced modalities. Acta odontologica Scandinavica. 2014;72(4):251-264.

17. Syriopoulos K, Sanderink GC, Velders XL, van der Stelt PF. Radiographic detection of approximal caries: a comparison of dental films and digital imaging systems. Dento maxillo facial radiology. 2000;29(5):312-318.

18. Jacobsen JH, Hansen B, Wenzel A, Hintze H. Relationship between histological and radiographic caries lesion depth measured in images from four digital radiography systems. Caries research. 2004;38(1):34-38.

19. Ekstrand KR, Luna LE, Promisiero L, et al. The reliability and accuracy of two methods for proximal caries detection and depth on directly visible proximal surfaces: an in vitro study. Caries research. 2011;45(2):93-99.

20. Wenzel A. Bitewing and digital bitewing radiography for detection of caries lesions. Journal of dental research. 2004;83 Spec No C:C72-75.

21. White SC, Yoon DC. Comparative performance of digital and conventional images for detecting proximal surface caries. Dento maxillo facial radiology. 1997;26(1):32-38.

22. Khan EA, Tyndall DA, Caplan D. Extraoral imaging for proximal caries detection: Bitewings vs scanogram. Oral surgery, oral medicine, oral pathology, oral radiology, and endodontics. 2004;98(6):730-737.

23. Wenzel A. Digital radiography and caries diagnosis. Dento maxillo facial radiology. 1998;27(1):311.

24. Wenzel A. Digital imaging for dental caries. Dental clinics of North America. 2000;44(2):319-338, vi.

25. Dove SB, McDavid WD. A comparison of conventional intra-oral radiography and computer imaging techniques for the detection of proximal surface dental caries. Dento maxillo facial radiology. 1992;21(3):127-134.

26. Wenzel A. A review of dentists' use of digital radiography and caries diagnosis with digital systems. Dento maxillo facial radiology. 2006;35(5):307-314.

27. Haiter-Neto F, dos Anjos Pontual A, Frydenberg M, Wenzel A. Detection of non-cavitated approximal caries lesions in digital images from seven solid-state receptors with particular focus on taskspecific enhancement filters. An ex vivo study in human teeth. Clinical oral investigations.

2008;12(3):217-223. 
28. Haiter-Neto F, Casanova MS, Frydenberg M, Wenzel A. Task-specific enhancement filters in storage phosphor images from the Vistascan system for detection of proximal caries lesions of known size. Oral surgery, oral medicine, oral pathology, oral radiology, and endodontics. 2009;107(1):116-121.

29. Moystad A, Svanaes DB, van der Stelt PF, et al. Comparison of standard and task-specific enhancement of Digora storage phosphor images for approximal caries diagnosis. Dento maxillo facial radiology. 2003;32(6):390-396.

30. Shrout MK, Russell CM, Potter BJ, Powell BJ, Hildebolt CF. Digital enhancement of radiographs: can it improve caries diagnosis? Journal of the American Dental Association (1939). 1996;127(4):469473.

31. Svanaes DB, Moystad A, Larheim TA. Approximal caries depth assessment with storage phosphor versus film radiography. Evaluation of the caries-specific Oslo enhancement procedure. Caries research. 2000;34(6):448-453.

32. Wenzel A. Computer-aided image manipulation of intraoral radiographs to enhance diagnosis in dental practice: a review. International dental journal. 1993;43(2):99-108.

33. Heaven TJ, Firestone AR, Weems RA. The effect of multiple examinations on the diagnosis of approximal caries and the restoration of approximal surfaces. Oral surgery, oral medicine, oral pathology, oral radiology, and endodontics. 1999;87(3):386-391.

34. Wall T GA. Very large dental practices seeing significant growth in market share. Health Policy Institute Research Brief. American Dental Association. 2015.

35. Zero $D$, Fontana $M$, Lennon AM. Clinical applications and outcomes of using indicators of risk in caries management. Journal of dental education. 2001;65(10):1126-1132.

36. Hintze $\mathrm{H}$, Wenzel A. A two-film versus a four-film bite-wing examination for caries diagnosis in adults. Caries research. 1999;33(5):380-386.

37. Arhami Dolatabadi A, Baratloo A, Rouhipour A, et al. Interpretation of Computed Tomography of the Head: Emergency Physicians versus Radiologists. Trauma monthly. 2013;18(2):86-89.

38. Shams N, Panahandeh N, Aghababa H, Shams B, Hemati E. Effects of education and experience on detection of proximal caries on digital radiographs. Oral Radiology. 2015:1-6.

39. Kamburoglu K, Kurt H, Kolsuz E, Oztas B, Tatar I, Celik HH. Occlusal caries depth measurements obtained by five different imaging modalities. Journal of digital imaging. 2011;24(5):804-813.

40. Soviero VM, Leal SC, Silva RC, Azevedo RB. Validity of MicroCT for in vitro detection of proximal carious lesions in primary molars. Journal of dentistry. 2012;40(1):35-40. 
41. Dowker SE, Elliott JC, Davis GR, Wassif HS. Longitudinal study of the three-dimensional development of subsurface enamel lesions during in vitro demineralisation. Caries research. 2003;37(4):237-245.

42. Ozkan G, Kanli A, Baseren NM, Arslan U, Tatar I. Validation of micro-computed tomography for occlusal caries detection: an in vitro study. Brazilian oral research. 2015;29(1):1-7.

43. Rathore S, Tyndall D, Wright T, Everett E. Comparison of Micro-CT and Histology in Dental Caries Diagnosis. Oral Surgery, Oral Medicine, Oral Pathology, Oral Radiology and Endodontics.105(4):e58-e59. 


\section{MANUSCRIPT}

\section{Introduction}

Dental caries is one of the most common diseases affecting man. It is a progressive and cumulative condition which when left untreated, destroys the hard tissues of the mouth and leads to increased patient morbidity and cost of treatment. ${ }^{1,2}$ A disproportionate amount of the caries burden in the US rests with those who do not have the necessary resources to correct dental related conditions. ${ }^{2}$ In 2012 total national dental expenditures in the US reached $\$ 111$ billion dollars. ${ }^{3}$ Since the loss of tooth structure due to caries often requires invasive, surgical restoration methods which lead to a cascade of treatments for the lifetime of the patient, prevention and early detection of disease which can be treated non-invasively will reduce the overall health care cost for the individual and society as a whole. ${ }^{1}$ Knowing this and the fact that previous caries history is the best predictor of future disease, dentists can help reduce the burden of disease by using any means of early detection at their disposal. ${ }^{35}$

In order to maximize patient benefit from a radiological exam in terms of detection of decay caused by oral bacteria, a radiographic detection system should be able to record the entire spectrum of the demineralization process. ${ }^{12}$ The detection system should be both sensitive to the subtle contrast changes taking place in the enamel and dentin, and specific for demineralization caused by cariogenic bacteria. ${ }^{12-15}$ By far the most commonly used and best accepted radiographic modality for detection of this process is the use of intraoral bitewing receptors evaluated by trained clinicians. ${ }^{36}$ However, observer performance, far from ideal, has remained relatively constant throughout the years despite advancements in imaging including digital technology. ${ }^{10,11}$

Many companies have introduced caries detection task specific image enhancement filters designed to improve detection of early lesions. Some studies have shown promise using these filters, while others studies show little to no improvement in early detection. ${ }^{27-32}$ Due to the numerous manufacturers of dental, digital imaging software and systems, many of these filters remain untested. In 
order to address the contrast limited identification of early demineralization, Sirona (Sirona Dental, Salzburg, Austria) has introduced a task-specific "General Dentistry" sharpening enhancement designed to aid the clinician in the detection of dental caries lesions. Similarly, MiPACS (Medicore Imaging, Charlotte, NC) has a "dentin-enamel" filter which also aims to increase contrast differences in the dentin and enamel. No research has been published to date testing the effect these filters have on the diagnosis of demineralization due to caries.

Observer performance in the detection of carious demineralization has remained fairly constant in the past few decades. ${ }^{10,11}$ No research to date has focused on the use of dual observers. Since the number of dental practices with more than one dentist has increased drastically in the past decade, this low tech detection aid may be an alternative to software enhancements. ${ }^{34}$

\section{Materials and Methods}

Institutional review board (IRB) approval was obtained to collect de-identified extracted human teeth and to perform observer sessions at the University of North Carolina at Chapel Hill (UNC) School of Dentistry (Study \#13-2843). Human premolar and molar teeth, obtained after extraction for necessary, indicated dental conditions in the Department of Oral and Maxillofacial Surgery at The UNC School of Dentistry, were assessed visually, tactilely, and radiographically to determine the presence or absence of proximal dental caries lesions. For the purposes of this paper, we defined demineralization as the radiographic sign of the dental caries process whether seen in the enamel or dentin. Demineralization status was classified as sound (no demineralization), initial (demineralization in the enamel or at/including the $D E J)$, or dentinal (demineralization past the DEJ). Teeth with proximal surfaces that were frankly cavitated, filled, or had defects were excluded. 29 teeth were selected for use in the study. Three of the teeth were used twice based on the fact that they demonstrated the "ideal" proximal lesion with the classic triangular shape, in which the base was at the outer surface of the enamel and the point extended to the DEJ. This allowed for a total of 64 surfaces to be viewed.

A dry human mandible with edentulous posterior segments and residual extraction sockets was used as an ex-vivo phantom for the study (Figure 1). The selected teeth were placed in the "19", "20", 
"29", and "30" positions and held in place by wax. Unrestored second molars and first premolars were mounted on distally and mesially, respectively, to the teeth to be viewed. The teeth were arranged so that contacts were anatomically correct and closed to simulate ideal dental alignment. Approximately $1 \mathrm{~cm}$ of boxing wax was placed around the mandible to simulate the attenuating characteristics of soft tissue.

Size 2 photostimulable phosphor plates (PSP) (Gendex, Hatfield, PA) were exposed with a Focus intraoral source (Instrumentarium Dental, Tuusula, Finland) at $70 \mathrm{kVp}, 7 \mathrm{~mA}, 0.2 \mathrm{~s}$, at $40 \mathrm{~cm}$ SID with $30 \mathrm{~cm}$ rectangular collimation. These settings were slightly lower than standard UNC radiographic protocol to adjust for the difference in attenuating characteristics of the wax used in our phantom and the soft tissue of a human face. The beam was placed at a perpendicular plane to the teeth in order to achieve images with non-overlapping contacts. Exposed plates were scanned by a ScanX IO ILE scanner (Air Techniques, Melville, NY) through MiPACS Dental Enterprise Viewer 3.1.1401 operating ScanX Plugin Version 1.2.8 (Meicore Imaging, Charlotte, NC). Settings on the scanner were Intraoral High (\#2), 16, bit, invert images, and Image Enhancement: Enable histogram stretch, upper histogram cut 0.2, Lower histogram cut 3.4, and Gamma correction 0.7. The images were saved first without any additional processing/enhancement and then saved after the "dentin-enamel' enhancement was applied resulting in two sets of images: one unenhanced and one "dentin-enamel" enhanced.

The teeth were also exposed on Schick 33 digital sensors with the same intraoral source at $70 \mathrm{kVp}, 7 \mathrm{~mA}, 0.05 \mathrm{~s}$, at $40 \mathrm{~cm}$ SID with $30 \mathrm{~cm}$ rectangular collimation interfaced with CDR DICOM for Windows Version 5.4.1658.5883 (Sirona Dental, Salzburg, Austria). These settings were used to achieve proper exposure based on the exposure indicator in the CDR DICOM software. Acquisition settings were Schick 33 High Resolution Acquisition, subtract dark image, and acquire 12-bit image. The same geometry was used in this sensor as was used for the PSP. Images were first saved unenhanced in the CDR DICOM software. The General Dentistry sharpening enhancement set at 35\%, which based on expert radiologist judgement to be an appropriate level of sharpening, was then applied and those images were saved resulting in two sets of images: one unenhanced and one "General Dentistry" sharpened. 
Micro-CT was used to establish ground truth. The teeth were individually imaged in $2 \mathrm{~cm}$ diameter poly-ether-imid tube $(0.7 \mathrm{~mm}$ wall thickness) with a SCANCO Medical $\mu \mathrm{CT} 40$ scanner (Scanco Medical AG, Bruttisellen, Switzerland) operating at 70kVp, $0.115 \mathrm{~mA}, 200 \mathrm{~s}$ scan time, with $0.5 \mathrm{~mm} \mathrm{Al}$ filtration, $5 \mu \mathrm{m}$ focal spot size, $24 \mu \mathrm{m}$ CMOS camera pitch, 1 sample per pixel, and convolution kernel 3 . Reconstruction was performed with a $20 \mu \mathrm{m}$ voxel size using Scanco Version 1.2a software (Scanco Medical AG, Bruttisellen, Switzerland).

Seven observers, all of whom had training in oral and maxillofacial radiology and clinical experience diagnosing carious lesions from bitewing radiographs, were recruited to be observers in the study. Six of the observers were radiology residents and 1 was a board certified oral and maxillofacial radiologist. An orientation session in which the primary investigator reviewed the study objectives, discussed the software to be used, instructed the participants on how to score for the detection tasks, and obtained informed consent from the observers was performed.

Observers were asked to score 3 diagnostic tasks on a 5-point scale in which $1=$ definitely not present, $2=$ probably not present, $3=$ unsure, $4=$ probably present, and $5=$ definitely present. The detection tasks were 1 . Determine if proximal a dental caries lesion is present, 2 . If a dental caries lesion is detected, does it extend into the dentin past the DEJ, and 3. Is cavitation present. Observers then viewed one set of images and recorded their scores. A washout period of about 2 weeks was used prior to viewing the next set of images and so on until all of the sets were viewed. A total of four sets of images: PSP unenhanced, PSP enhanced, Schick 33 unenhanced, and Schick 33 enhanced were randomly viewed. The observers were allowed to adjust for brightness and contrast, but were not allowed to apply any type of filters.

Three sets of two observers working together viewed the PSP unfiltered images and were asked to decide on a score for the 3 diagnostic tasks. If the two individuals did not agree at first, a discussion between the two was performed in order to come to a consensus.

Observation sessions were conducted in a dimly lit radiology viewing room. Dual monitor workstations with Lenovo LT2252p monitors (Lenovo, Beijing, China) were used to display the images. The monitors underwent TCG-18 test pattern quality control checks prior to the sessions. The primary 
investigator was available at all of the sessions to answer any questions that arose. MiPACS Dental Enterprise Viewer 3.1.1401 (Medicore Imaging, Charlotte, NC) was used for viewing the PSP images. CDR DICOM for Windows Version 5.4.1658.5883 (Sirona Dental, Salzburg, Austria) was used for viewing the Schick 33 images. Micro-CT images were analyzed and ground truth was recorded for each of the detection tasks.

Observation scores and ground truth data were used to construct receiver operating characteristic (ROC) curves via a web-based ROC analysis tool from Johns Hopkins University (www.jrocfit.org). Area under the curve $\left(A_{z}\right)$ scores were recorded. Sensitivity and specificity were calculated in SPSS (IBM, Armonk, New York). For dental caries lesion presence a response of 3, 4, and 5 was considered to be positive. For dentin extension and cavitation presence, a score of 4 and 5 was considered to be positive. Intra-observer reliability was calculated using a linear weighted Kappa calculator (vassarstats.net). Two of the observers were not able to complete the reliability portion of the test. This only five observers were used to calculate weighted Kappa. Extent of the effect of observers, receptors, and filters on the various statistical tests was calculated using linear regression in SPSS. Both individual and diagnostic task pooled data were analyzed. A $p$-value of $<0.05$ was considered to be statistically significant.

\section{Results}

Of the 64 proximal surfaces, 34 surfaces were demineralized of which 15 were enamel lesions extending to and including the DEJ, 19 lesions extended into the dentin past the DEJ, and 11 lesions were cavitated (Table 1). For detection of dental caries lesions observers performed better on the PSP than the Schick 33 sensors $(p=0.007)$. Filters and receptors had no effect on the accuracy of dentinal extension or cavitation (Tables 7 and 8). No differences between dual and single observers were seen in any of the detection tasks (Table 9). PSP provided a more sensitive viewing platform for detecting caries lesions while the Schick 33 sensor was more specific $(p=0.032)$ (Table 20). Unfiltered images were more specific for caries lesion detection (Table 20). Average weighted Kappa values ranged from 0.56- 
0.85 indicating good to nearly perfect agreement (Table 16). For dentinal extension, observers performed more reliably on the Schick 33 sensors $(p=0.011)$ (Table 18).

\section{Discussion}

Diagnostic accuracy for the presence of dental caries lesions, extension into dentin, and presence of cavitation is crucial for developing the most appropriate treatment plan for the patient. Diagnosing small incipient lesions prior to cavitation allows for non-surgical treatment with fluoride varnish which in turn lowers patient cost and prevents loss of tooth structure via surgical means. ${ }^{9}$ Despite continued advances in technology, which now includes task specific image enhancements, no definitive improvement in caries detection has been observed since early film based systems. ${ }^{13-15}$

In this study, detectors, filters, and observers had no effect on the accuracy of diagnosing the extension into dentin and cavitation caused by dental caries. Between the two detector systems, dental caries lesion presence was more accurately diagnosed on PSP rather than the Schick 33 sensor, while the Schick sensor was more specific for this task. This may be the result of inherent image quality differences, but is unlikely to be a clinically significant result. In our study, observers trained in radiology viewed the images under ideal viewing conditions. Radiologists and radiology residents have been shown to be more accurate than non-radiologist dentists/physicians in certain diagnostic tasks. ${ }^{37,38}$ All $A_{z}$ values were unusually high for the diagnostic tasks. The use of non-ideal viewing conditions, such as those seen in a typical dental operatory by general dentists, may result in different results. Specificity was near perfect for many of the diagnostic tasks. This likely inflated $A_{z}$ values and could be due to a sample that was not difficult enough for oral radiologists/residents. A previous study by Gaalaas came to the same conclusion. ${ }^{39}$

One may assume that having two experienced observers look at images and discuss their thoughts as to possible sources of disagreement would lead to an increase in accuracy of diagnosis. The results of this study suggest that this is not the case. The average $A_{z}$ value for dual observers was less than that of single observers, but the difference was not statistically significant. Due to the limited 
number of pairs of observers, this result should be interpreted with caution. Future work will include more pairs of observers.

ROC was used to determine accuracy because it effectively removes differences in observers' decision making thresholds. ${ }^{40-42}$ Three was selected to be a positive response in determining whether a dental caries lesion was present. We chose this value because we believe there to be little consequence to a false positive diagnosis when looking at one radiograph and being asked if a lesion is present. The only treatment outcome should be to place fluoride varnish on the tooth which is an inexpensive, noninvasive treatment. Without knowing status of activity, dentin extension, and cavitation presence, we believe that the treating clinician should not be surgically intervening based on finding demineralization without cavitation on one radiograph. For extension into dentin and presence of cavitation a three was considered a negative. We believe that a higher false negative rate is more acceptable in order to reduce unnecessary surgical interventions which are costlier treatments and involve irreversible procedures. This thresholding variation saw the PSP being the more sensitive system with the Schick 33 system being more specific for the detection of dental caries lesions.

Micro-CT was used as the gold standard in this experiment rather than histologic sectioning. Several studies have shown equivalent accuracy in evaluating for the presence of caries lesions, dentin extension, and cavitation between the two techniques. ${ }^{43-46}$ Histologic evaluation is a destructive process that may prevent small enamel lesions from being detected or overestimate penetration due to staining. ${ }^{47}$ Intra-observer reliability was good to nearly perfect for all tasks. One difference seen was that observers were more reliable using the Schick 33 sensors to diagnose dentin extension. Whether a clinical significance to this is present is a matter of debate. All of the weighted Kappa scores were above 0.5 .

In conclusion, little to no clinically significant differences were seen among observers, receptors, or filters. Use of the studied enhancement software cannot be recommended on a routine basis based on the results of the study. Further testing of dual observers is warranted as a limited number of groups was used. Repeated experiments under non-ideal conditions with general dentists is also warranted to see if any changes in the results are observed. 


\section{REFERENCES}

1. Schwendicke F, Meyer-Lueckel H, Stolpe M, Dorfer CE, Paris S. Costs and effectiveness of treatment alternatives for proximal caries lesions. PloS one. 2014;9(1):e86992.

2. Services UDoHaH. Oral Health in America: A Report of the Surgeon General. U.S. Department of Health and Human Services, National Institute of Dental and Craniofacial Research, National Institutes of Health 2000.

3. Wall T, Nasseh K., Vujicic M. U.S. Dental Spending Remains Flat through 2012. Health Policy Resources Center Research Brief. American Dental Association.

4. Diagnosis and management of dental caries throughout life. National Institutes of Health Consensus Development Conference statement, March 26-28, 2001. Journal of dental education. 2001;65(10):1162-1168.

5. Selwitz RH, Ismail Al, Pitts NB. Dental caries. Lancet (London, England). 2007;369(9555):51-59.

6. Baelum V. What is an appropriate caries diagnosis? Acta odontologica Scandinavica. 2010;68(2):65-79.

7. Kidd EA, Fejerskov $\mathrm{O}$. What constitutes dental caries? Histopathology of carious enamel and dentin related to the action of cariogenic biofilms. Journal of dental research. 2004;83 Spec No C:C35-38.

8. Stahl J, Zandona AF. Rationale and protocol for the treatment of non-cavitated smooth surface carious lesions. General dentistry. 2007;55(2):105-111.

9. Lenzi TL, Montagner AF, Soares FZ, de Oliveira Rocha R. Are topical fluorides effective for treating incipient carious lesions?: A systematic review and meta-analysis. Journal of the American Dental Association (1939). 2016;147(2):84-91.e81.

10. Senel B, Kamburoglu K, Ucok O, Yuksel SP, Ozen T, Avsever H. Diagnostic accuracy of different imaging modalities in detection of proximal caries. Dento maxillo facial radiology. 2010;39(8):501-511.

11. Dove SB. Radiographic diagnosis of dental caries. Journal of dental education. 2001;65(10):985990.

12. Zandona AF, Zero DT. Diagnostic tools for early caries detection. Journal of the American Dental Association (1939). 2006;137(12):1675-1684; quiz 1730.

13. Huda W, Rill LN, Benn DK, Pettigrew JC. Comparison of a photostimulable phosphor system with film for dental radiology. Oral surgery, oral medicine, oral pathology, oral radiology, and endodontics. 1997;83(6):725-731.

14. Kashima I. Computed radiography with photostimulable phosphor in oral and maxillofacial radiology. Oral surgery, oral medicine, oral pathology, oral radiology, and endodontics. 1995;80(5):577598. 
15. Webber RL, Benton PA, Cvar JF, Ryge G. Diagnostic significance of intratissue contrast in bitewing radiographs. Oral surgery, oral medicine, and oral pathology. 1969;28(3):352-358.

16. Wenzel A. Radiographic display of carious lesions and cavitation in approximal surfaces: Advantages and drawbacks of conventional and advanced modalities. Acta odontologica Scandinavica. 2014;72(4):251-264.

17. Syriopoulos K, Sanderink GC, Velders XL, van der Stelt PF. Radiographic detection of approximal caries: a comparison of dental films and digital imaging systems. Dento maxillo facial radiology. 2000;29(5):312-318.

18. Jacobsen JH, Hansen B, Wenzel A, Hintze H. Relationship between histological and radiographic caries lesion depth measured in images from four digital radiography systems. Caries research. 2004;38(1):34-38.

19. Ekstrand KR, Luna LE, Promisiero L, et al. The reliability and accuracy of two methods for proximal caries detection and depth on directly visible proximal surfaces: an in vitro study. Caries research. 2011;45(2):93-99.

20. Wenzel A. Bitewing and digital bitewing radiography for detection of caries lesions. Journal of dental research. 2004;83 Spec No C:C72-75.

21. White SC, Yoon DC. Comparative performance of digital and conventional images for detecting proximal surface caries. Dento maxillo facial radiology. 1997;26(1):32-38.

22. Khan EA, Tyndall DA, Caplan D. Extraoral imaging for proximal caries detection: Bitewings vs scanogram. Oral surgery, oral medicine, oral pathology, oral radiology, and endodontics. 2004;98(6):730-737.

23. Wenzel A. Digital radiography and caries diagnosis. Dento maxillo facial radiology. 1998;27(1):311.

24. Wenzel A. Digital imaging for dental caries. Dental clinics of North America. 2000;44(2):319-338, vi.

25. Dove SB, McDavid WD. A comparison of conventional intra-oral radiography and computer imaging techniques for the detection of proximal surface dental caries. Dento maxillo facial radiology. 1992;21(3):127-134.

26. Wenzel A. A review of dentists' use of digital radiography and caries diagnosis with digital systems. Dento maxillo facial radiology. 2006;35(5):307-314.

27. Haiter-Neto F, dos Anjos Pontual A, Frydenberg M, Wenzel A. Detection of non-cavitated approximal caries lesions in digital images from seven solid-state receptors with particular focus on taskspecific enhancement filters. An ex vivo study in human teeth. Clinical oral investigations.

2008;12(3):217-223. 
28. Haiter-Neto F, Casanova MS, Frydenberg M, Wenzel A. Task-specific enhancement filters in storage phosphor images from the Vistascan system for detection of proximal caries lesions of known size. Oral surgery, oral medicine, oral pathology, oral radiology, and endodontics. 2009;107(1):116-121.

29. Moystad A, Svanaes DB, van der Stelt PF, et al. Comparison of standard and task-specific enhancement of Digora storage phosphor images for approximal caries diagnosis. Dento maxillo facial radiology. 2003;32(6):390-396.

30. Shrout MK, Russell CM, Potter BJ, Powell BJ, Hildebolt CF. Digital enhancement of radiographs: can it improve caries diagnosis? Journal of the American Dental Association (1939). 1996;127(4):469473.

31. Svanaes DB, Moystad A, Larheim TA. Approximal caries depth assessment with storage phosphor versus film radiography. Evaluation of the caries-specific Oslo enhancement procedure. Caries research. 2000;34(6):448-453.

32. Wenzel A. Computer-aided image manipulation of intraoral radiographs to enhance diagnosis in dental practice: a review. International dental journal. 1993;43(2):99-108.

33. Heaven TJ, Firestone AR, Weems RA. The effect of multiple examinations on the diagnosis of approximal caries and the restoration of approximal surfaces. Oral surgery, oral medicine, oral pathology, oral radiology, and endodontics. 1999;87(3):386-391.

34. Wall T GA. Very large dental practices seeing significant growth in market share. Health Policy Institute Research Brief. American Dental Association. 2015.

35. Zero $D$, Fontana $M$, Lennon AM. Clinical applications and outcomes of using indicators of risk in caries management. Journal of dental education. 2001;65(10):1126-1132.

36. Hintze $\mathrm{H}$, Wenzel A. A two-film versus a four-film bite-wing examination for caries diagnosis in adults. Caries research. 1999;33(5):380-386.

37. Shams N, Panahandeh N, Aghababa H, Shams B, Hemati E. Effects of education and experience on detection of proximal caries on digital radiographs. Oral Radiology. 2015:1-6.

38. Arhami Dolatabadi A, Baratloo A, Rouhipour A, et al. Interpretation of Computed Tomography of the Head: Emergency Physicians versus Radiologists. Trauma monthly. 2013;18(2):86-89.

39. Gaalaas L, Tyndall D, Mol A, Everett ET, Bangdiwala A. Ex vivo evaluation of new 2D and 3D dental radiographic technology for detecting caries. Dento maxillo facial radiology. 2016;45(3):20150281.

40. Metz CE. ROC methodology in radiologic imaging. Investigative radiology. 1986;21(9):720-733.

41. Metz CE. ROC analysis in medical imaging: a tutorial review of the literature. Radiological physics and technology. 2008;1(1):2-12. 
42. van Erkel AR, Pattynama PM. Receiver operating characteristic (ROC) analysis: basic principles and applications in radiology. European journal of radiology. 1998;27(2):88-94.

43. Kamburoglu K, Kurt H, Kolsuz E, Oztas B, Tatar I, Celik HH. Occlusal caries depth measurements obtained by five different imaging modalities. Journal of digital imaging. 2011;24(5):804-813.

44. Soviero VM, Leal SC, Silva RC, Azevedo RB. Validity of MicroCT for in vitro detection of proximal carious lesions in primary molars. Journal of dentistry. 2012;40(1):35-40.

45. Dowker SE, Elliott JC, Davis GR, Wassif HS. Longitudinal study of the three-dimensional development of subsurface enamel lesions during in vitro demineralisation. Caries research. 2003;37(4):237-245.

46. Ozkan G, Kanli A, Baseren NM, Arslan U, Tatar I. Validation of micro-computed tomography for occlusal caries detection: an in vitro study. Brazilian oral research. 2015;29(1):1-7.

47. Rathore S, Tyndall D, Wright T, Everett E. Comparison of Micro-CT and Histology in Dental Caries Diagnosis. Oral Surgery, Oral Medicine, Oral Pathology, Oral Radiology and Endodontics.105(4):e58-e59. 


\section{Tables and Figures}

Figure 1: Photo of the mandibular phantom

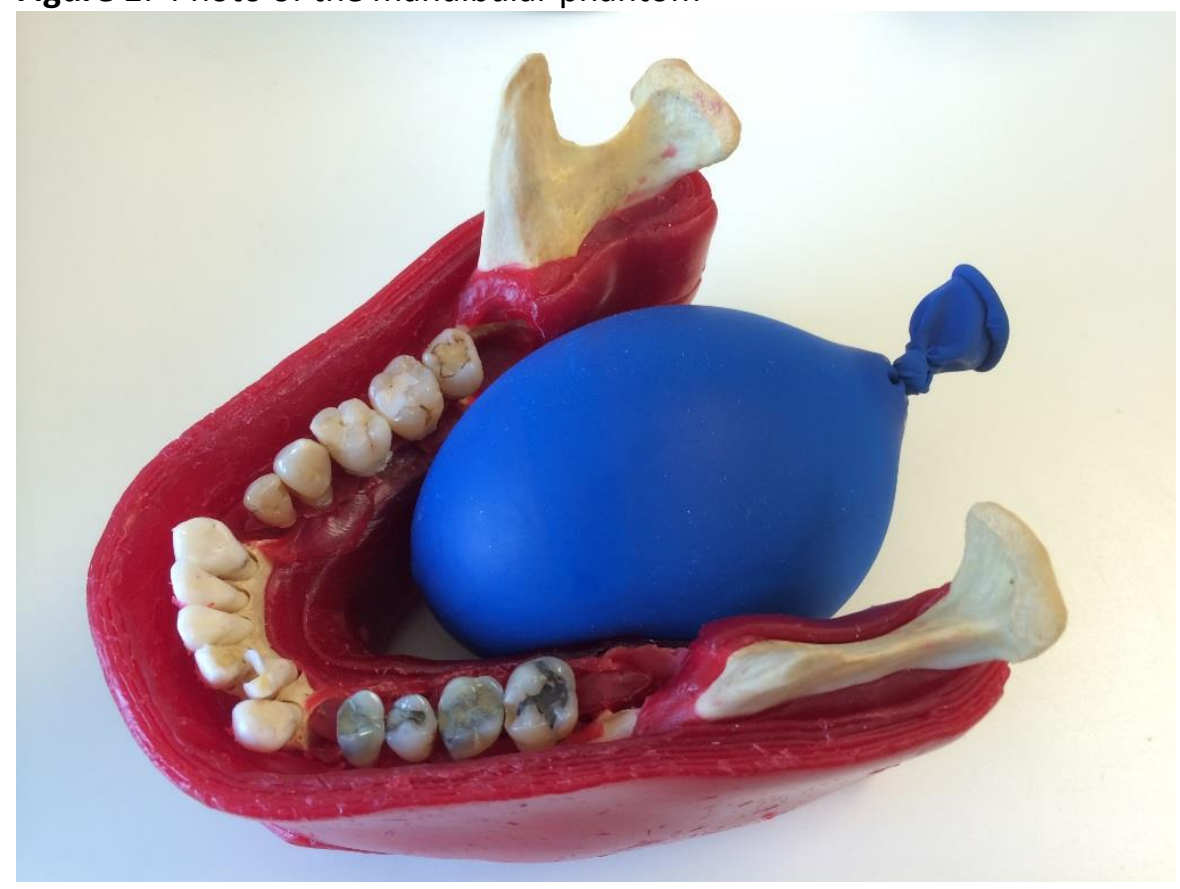

Table 1: Proximal surface ground truth status by micro-CT

Sound 30

Total demineralized (enamel or dentin) 34

Enamel 15

Dentin (past DEJ) 19

Cavitated 11 
Table 2. Dental caries lesion detection Az values

\begin{tabular}{|c|c|c|c|c|c|}
\hline \multicolumn{6}{|c|}{ Modality } \\
\hline Observer & PSP unfil & PSP fil & Schick unfil & Schick fil & Mean \\
\hline 1 & 0.84 & 0.85 & 0.76 & 0.81 & 0.82 \\
\hline 2 & 0.82 & 0.86 & 0.82 & 0.81 & 0.83 \\
\hline 3 & 0.79 & 0.82 & 0.77 & 0.78 & 0.79 \\
\hline 4 & 0.81 & 0.81 & 0.79 & 0.80 & 0.80 \\
\hline 5 & 0.78 & 0.85 & 0.74 & 0.70 & 0.77 \\
\hline 6 & 0.74 & 0.77 & 0.72 & 0.75 & 0.75 \\
\hline 7 & 0.82 & 0.87 & 0.82 & 0.80 & 0.83 \\
\hline Mean & 0.80 & 0.83 & 0.77 & 0.78 & \\
\hline
\end{tabular}

\section{POOLED DENTAL CARIES LESION ROC}

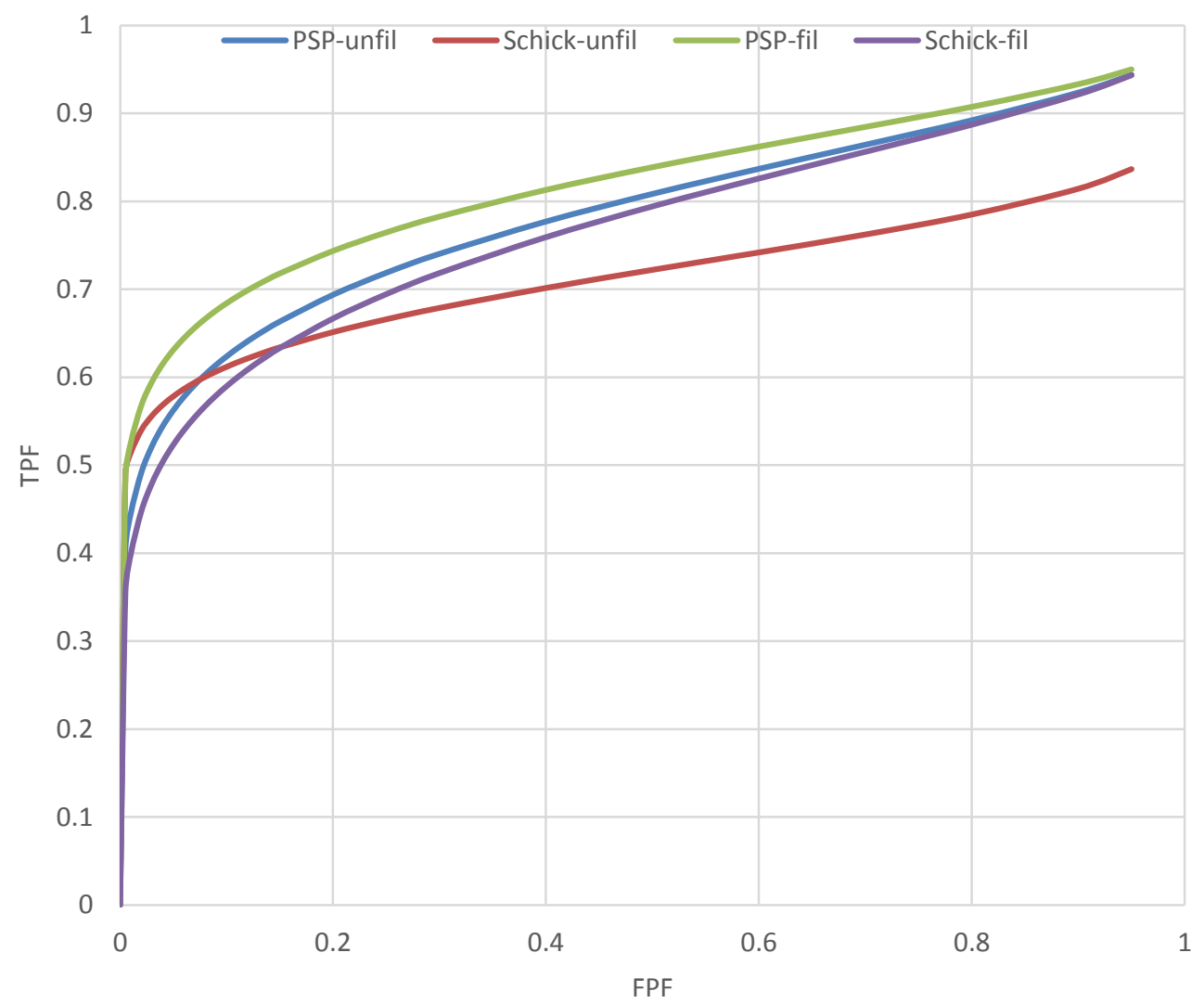

Figure 2: Pooled dental caries detection ROC curves 
Table 3. Dentin Extension Az values

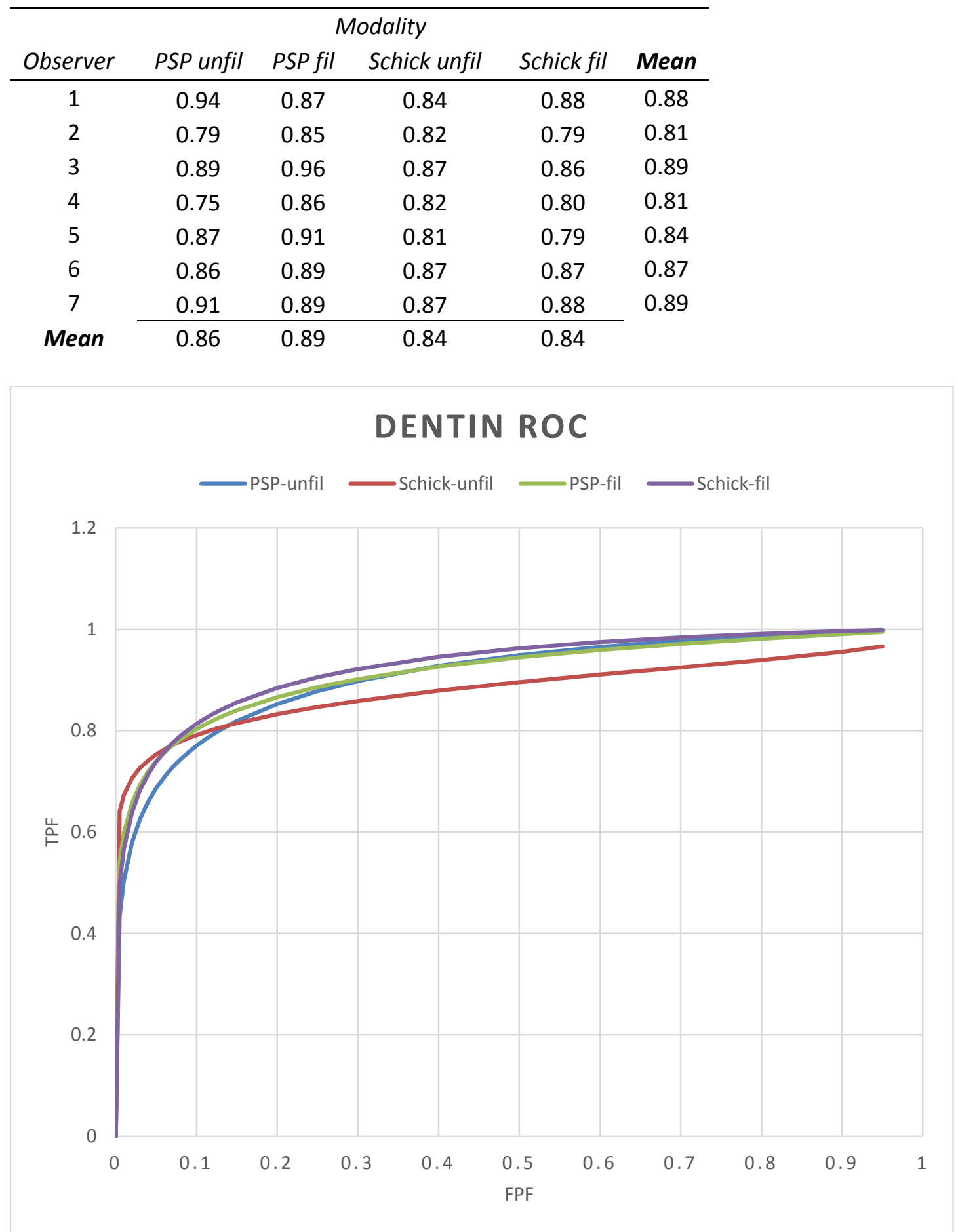

Figure 3: Pooled dentin extension ROC curves 
Table 4. Cavitation Az values

\begin{tabular}{cccccc}
\hline & \multicolumn{5}{c}{ Modality } \\
Observer & PSP unfil & PSP fil & Schick unfil & Schick fil & Mean \\
\hline 1 & 0.93 & 0.98 & 0.94 & 0.99 & 0.96 \\
2 & 0.95 & 0.85 & 0.90 & 0.81 & 0.88 \\
3 & 0.94 & 0.97 & 0.99 & 0.97 & 0.97 \\
4 & 0.93 & 0.99 & 0.99 & 0.99 & 0.98 \\
5 & 0.80 & 0.88 & 0.89 & 0.80 & 0.84 \\
6 & 0.98 & 0.96 & 0.94 & 0.94 & 0.96 \\
7 & 0.99 & 0.99 & 0.95 & 0.99 & 0.98 \\
\cline { 2 - 4 } Mean & 0.93 & 0.95 & 0.94 & 0.93 &
\end{tabular}

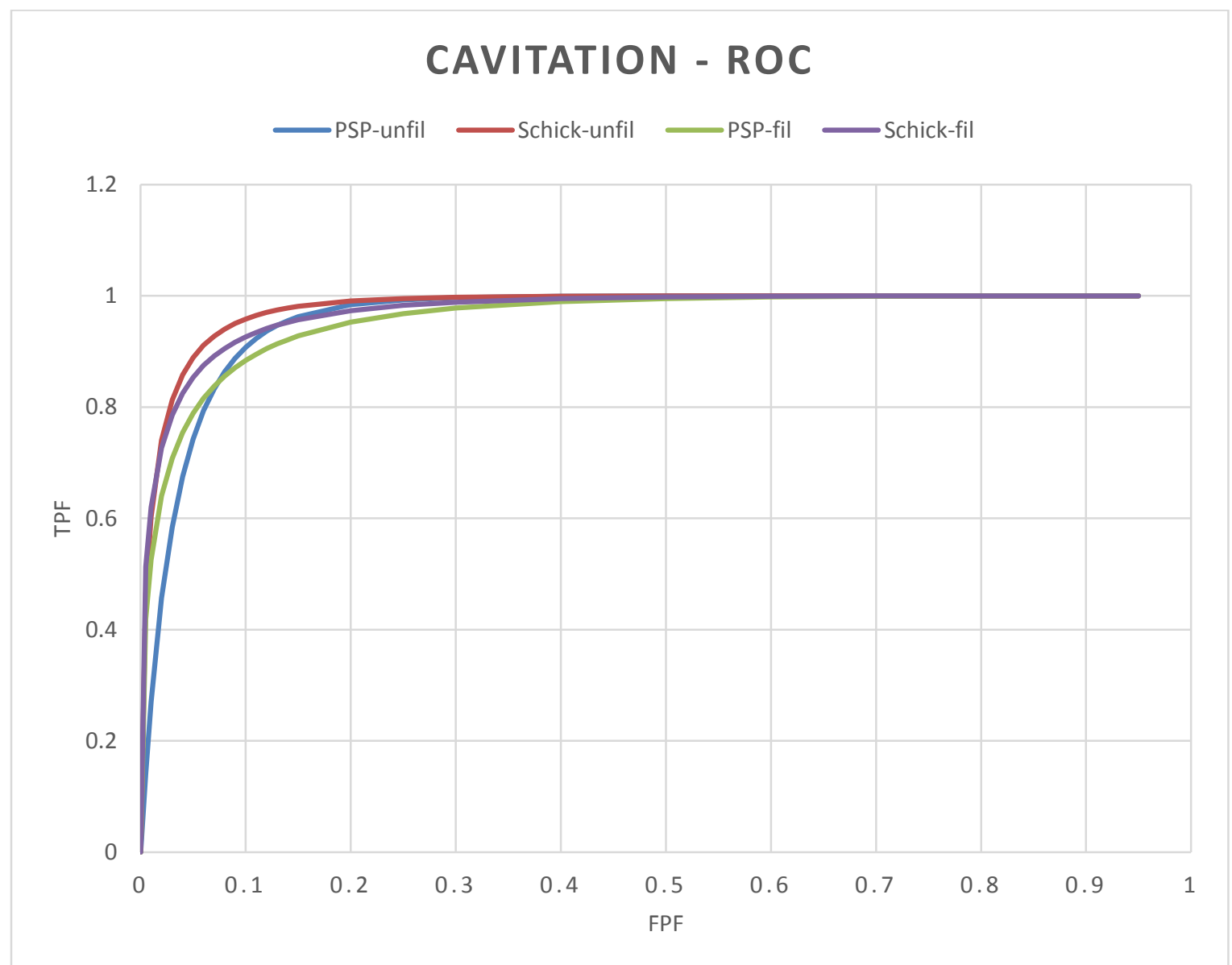

Figure 4: Pooled cavitation presence ROC curves 
Table 5. Dual Observer Az values

\begin{tabular}{ccccc} 
Group & Demin & Dentin & Cavitation & Mean \\
\hline 1 & 0.76 & 0.84 & 0.94 & 0.85 \\
2 & 0.77 & 0.74 & 0.76 & 0.76 \\
3 & 0.77 & 0.90 & 0.99 & 0.89 \\
\cline { 2 - 4 } Mean & 0.77 & 0.83 & 0.90 &
\end{tabular}

Table 6: Linear Regression for $A_{z}$ for dental caries detection

\begin{tabular}{ccccc} 
Term & Coef & SE Coef & $t$ & $P$ \\
\hline Constant & 0.850 & & 26.174 & 0.000 \\
Observer & -0.005 & -0.260 & -1.582 & 0.127 \\
Receptor & -0.040 & -0.485 & -2.954 & 0.007 \\
Filter & 0.019 & 0.225 & 1.371 & 0.183
\end{tabular}

Table 7: Linear Regression for $A_{z}$ for extension into dentin

\begin{tabular}{ccccc} 
Term & Coef & SE Coef & $t$ & $P$ \\
\hline Constant & 0.875 & & 20.807 & 0.000 \\
Observer & 0.003 & 0.129 & 0.692 & 0.496 \\
Receptor & 0.034 & -0.357 & -1.913 & 0.068 \\
Filter & 0.014 & 0.144 & 0.774 & 0.447
\end{tabular}

Table 8: Linear Regression for $A_{2}$ for cavitation presence

\begin{tabular}{ccccc}
\hline Term & Coef & SE Coef & $t$ & $P$ \\
\hline Constant & .930 & & 16.217 & 0.000 \\
Observer & 0.003 & 0.109 & 0.537 & 0.596 \\
Receptor & -0.004 & -0.030 & -0.149 & 0.883 \\
Filter & -0.001 & 0.006 & -0.030 & 0.976
\end{tabular}

Table 9: Linear Regression for Dual Observers

\begin{tabular}{ccccc} 
Term & Coef & SE Coef & $t$ & $P$ \\
\hline Constant & 0.745 & & 20.296 & 0.000 \\
Observer & -0.004 & -0.149 & -1.063 & 0.297 \\
Task & 0.066 & 0.668 & 4.757 & 0
\end{tabular}


Table 10. Caries lesion detection Sensitivity

\begin{tabular}{cccccc}
\hline \multirow{5}{*}{ Observer } & PSP unfil & PSP fil & Schick unfil & Schick fil & Mean \\
\hline 1 & 79.40 & 82.40 & 47.10 & 52.90 & 65.45 \\
2 & 76.50 & 82.40 & 58.80 & 64.70 & 70.60 \\
3 & 70.60 & 67.60 & 52.90 & 58.80 & 62.48 \\
4 & 64.70 & 67.60 & 41.20 & 44.10 & 54.40 \\
5 & 55.90 & 76.50 & 55.90 & 52.90 & 60.30 \\
6 & 47.10 & 50.00 & 41.20 & 44.10 & 45.60 \\
7 & 61.80 & 76.50 & 55.90 & 55.90 & 62.53 \\
\cline { 2 - 5 } Mean & 65.14 & 71.86 & 50.43 & 53.34 &
\end{tabular}

Table 11. Caries lesion detection Specificity

\begin{tabular}{cccccc}
\hline \multirow{2}{*}{ Observer } & PSP unfil & PSP fil & Schick unfil & Schick fil & Mean \\
\hline 1 & 76.70 & 73.30 & 96.70 & 100.00 & 86.68 \\
2 & 96.70 & 80.00 & 100.00 & 100.00 & 94.18 \\
3 & 86.70 & 90.00 & 100.00 & 96.70 & 93.35 \\
4 & 90.00 & 83.30 & 100.00 & 100.00 & 93.33 \\
5 & 90.00 & 76.70 & 96.70 & 86.70 & 87.53 \\
6 & 100.00 & 96.70 & 100.00 & 100.00 & 99.18 \\
7 & 93.30 & 80.00 & 100.00 & 83.30 & 89.15 \\
Mean & 90.49 & 82.86 & 99.06 & 95.24 &
\end{tabular}

Table 12. Dentin extension Sensitivity

\begin{tabular}{cccccc}
\hline \multirow{5}{*}{ Observer } & PSP unfil & PSP fil & Schick unfil & Schick fil & Mean \\
\hline 1 & 63.20 & 72.20 & 47.40 & 57.90 & 60.18 \\
2 & 57.90 & 68.40 & 52.60 & 42.10 & 55.25 \\
3 & 68.40 & 73.70 & 63.20 & 63.20 & 67.13 \\
4 & 47.40 & 47.40 & 52.60 & 36.80 & 46.05 \\
5 & 47.40 & 73.70 & 63.20 & 52.60 & 59.23 \\
6 & 42.10 & 57.90 & 42.10 & 47.40 & 47.38 \\
7 & 52.60 & 68.40 & 52.60 & 63.20 & 59.20 \\
Mean & 54.14 & 65.96 & 53.39 & 51.89 &
\end{tabular}


Table 13. Dentin extension Specificity

\begin{tabular}{cccccc}
\hline \multirow{5}{*}{ Observer } & PSP unfil & PSP fil & Schick unfil & Schick fil & Mean \\
\hline 1 & 97.80 & 95.60 & 100.00 & 97.80 & 97.80 \\
2 & 100.00 & 97.80 & 100.00 & 100.00 & 99.45 \\
3 & 95.60 & 100.00 & 100.00 & 100.00 & 98.90 \\
4 & 100.00 & 100.00 & 100.00 & 100.00 & 100.00 \\
5 & 100.00 & 100.00 & 100.00 & 100.00 & 100.00 \\
6 & 100.00 & 100.00 & 100.00 & 100.00 & 100.00 \\
7 & 100.00 & 95.60 & 100.00 & 97.80 & 98.35 \\
Mean & 99.06 & 98.43 & 100.00 & 99.37 &
\end{tabular}

Table 14. Cavitation Sensitivity

\begin{tabular}{|c|c|c|c|c|c|}
\hline \multirow[b]{2}{*}{ Observer } & \multicolumn{4}{|c|}{ Modality } & \multirow[b]{2}{*}{ Mean } \\
\hline & PSP unfil & PSP fil & Schick unfil & Schick fil & \\
\hline 1 & 63.60 & 90.00 & 72.70 & 72.70 & 74.75 \\
\hline 2 & 63.60 & 45.50 & 45.50 & 45.50 & 50.03 \\
\hline 3 & 81.80 & 90.90 & 81.80 & 63.60 & 79.53 \\
\hline 4 & 81.80 & 100.00 & 90.90 & 81.80 & 88.63 \\
\hline 5 & 27.30 & 63.60 & 45.50 & 54.50 & 47.73 \\
\hline 6 & 63.60 & 63.60 & 54.50 & 54.50 & 59.05 \\
\hline 7 & 54.50 & 63.60 & 54.50 & 63.60 & 59.05 \\
\hline Mean & 62.31 & 73.89 & 63.63 & 62.31 & \\
\hline
\end{tabular}

Table 15. Cavitation Specificity

\begin{tabular}{cccccc}
\hline & \multicolumn{5}{c}{ Modality } \\
Observer & PSP unfil & PSP fil & Schick unfil & Schick fil & Mean \\
\hline 1 & 92.50 & 96.20 & 98.10 & 98.10 & 96.23 \\
2 & 100.00 & 100.00 & 100.00 & 100.00 & 100.00 \\
3 & 90.60 & 90.60 & 96.20 & 98.10 & 93.88 \\
4 & 96.20 & 94.30 & 96.20 & 98.10 & 96.20 \\
5 & 100.00 & 96.20 & 100.00 & 100.00 & 99.05 \\
6 & 100.00 & 98.10 & 100.00 & 100.00 & 99.53 \\
7 & 100.00 & 98.10 & 100.00 & 100.00 & 99.53 \\
Mean & 97.04 & 96.21 & 98.64 & 99.19 &
\end{tabular}

Table 16. Intra-Observer Reliability (average kappa)

\begin{tabular}{cccc} 
& Caries & Dentin & Cavitation \\
\cline { 2 - 4 } PSP unfil & 0.746 & 0.692 & 0.670 \\
PSP fil & 0.558 & 0.650 & 0.748 \\
Schick unil & 0.706 & 0.790 & 0.682 \\
Schick fil & 0.808 & 0.864 & 0.782
\end{tabular}


Table 17: Linear Regression for dental caries Intra-Observer Reliability

\begin{tabular}{ccccc} 
Term & Coef & SE Coef & $t$ & $P$ \\
\hline Constant & 0.532 & & 3.764 & 0.002 \\
Observer & 0.019 & 0.249 & 1.153 & 0.266 \\
Receptor & 0.105 & 0.402 & 1.856 & 0.082 \\
Filter & -0.043 & -0.164 & -0.76 & 0.458
\end{tabular}

Table 18: Linear Regression for dentin Intra-Observer Reliability

\begin{tabular}{ccccc} 
Term & Coef & SE Coef & $t$ & $P$ \\
\hline Constant & 0.401 & & 2.937 & 0.01 \\
Observer & 0.022 & 0.265 & 1.356 & 0.194 \\
Receptor & .560 & 0.559 & 2.856 & 0.011 \\
Filter & 0.016 & 0.057 & 0.293 & 0.773
\end{tabular}

Table 19: Linear Regression for cavitation Intra-Observer Reliability

\begin{tabular}{ccccc} 
Term & Coef & SE Coef & $\mathrm{t}$ & $P$ \\
\hline Constant & 0.535 & & 3.144 & 0.006 \\
Observer & 0.004 & 0.05 & 0.212 & 0.835 \\
Receptor & 0.023 & 0.08 & 0.338 & 0.74 \\
Filter & 0.089 & 0.309 & 1.307 & 0.21
\end{tabular}

Table 20: Linear Regression for dental caries Specificity

\begin{tabular}{ccccc} 
Term & Coef & SE Coef & $t$ & $P$ \\
\hline Constant & 83.118 & & 13.797 & 0 \\
Observer & 0.414 & 0.096 & 0.66 & 0.516 \\
Receptor & 10.479 & 0.608 & 4.171 & 0 \\
Filter & -5.721 & -0.332 & -0.2277 & 0.032
\end{tabular}

